\title{
A Procurement Performance Model for Construction Frameworks
}

\author{
Terence Y M Lam ${ }^{1}$ and Keith S Gale ${ }^{2}$ \\ ${ }^{1}$ Senior Lecturer, School of Natural \& Built Environment, University of South Australia, Adelaide SA5000, Australia, E- \\ mail: terence.lam@unisa.edu.au (corresponding author). \\ ${ }^{2}$ Visiting Research Fellow, Department of Engineering \& the Built Environment, Anglia Ruskin University, \\ Chelmsford, CB21 5AE, UK, E-mail: keith.gale@hants.gov.uk
}

Project Management

Excellent Paper of EPPM2014 Conference

Received January 21, 2015; received revision May 8, 2015; accepted May 9, 2015

Available online May 22, 2015

\begin{abstract}
Collaborative construction frameworks have been developed in the United Kingdom (UK) to create longer term relationships between clients and suppliers in order to improve project outcomes. Research undertaken into highways maintenance set within a major county council has confirmed that such collaborative procurement methods can improve time, cost and quality of construction projects. Building upon this and examining the same single case, this research aims to develop a performance model through identification of performance drivers in the whole project delivery process including pre and post contract phases. A priori performance model based on operational and sociological constructs was proposed and then checked by a pilot study. Factor analysis and central tendency statistics from the questionnaires as well as content analysis from the interview transcripts were conducted. It was confirmed that long term relationships, financial and non-financial incentives and stronger communication are the sociological behaviour factors driving performance. The interviews also established that key performance indicators (KPIs) can be used as an operational measure to improve performance. With the posteriori performance model, client project managers can effectively collaboratively manage contractor performance through procurement measures including use of longer term and KPIs for the contract so that the expected project outcomes can be achieved. The findings also make significant contribution to construction framework procurement theory by identifying the interrelated sociological and operational performance drivers. This study is set predominantly in the field of highways civil engineering. It is suggested that building based projects or other projects that share characteristics are grouped together and used for further research of the phenomena discovered.
\end{abstract}

Keywords: Public sector, collaborative frameworks, performance drivers.

\section{Introduction}

The construction industry is a significant contributor to the economy of the United Kingdom (UK). In 2010, the Gross Value Added (GVA) of the construction industry was estimated to be $£ 110$ billion, representing $6.8 \%$ of the total GVA of the UK (ONS, 2010). Of the total estimated value of the industry, $£ 41$ billion is financed by the public sector (accounting for $37 \%$ of all construction expenditure). The importance of the construction industry and its influence upon the overall economy of the UK is specifically mentioned within the Government Construction Strategy (Cabinet Office, 2011).

The need to improve performance is reinforced by providing a holistic vision of the industry through the Industrial Strategy: government and industry in partnership, Construction 2025 (BIS, 2013). Development and growth of UK construction within overseas markets are encouraged whilst providing challenging targets for domestic consumption. Such performance improvement suggested a 33\% reduction in the initial cost of construction and the whole life cost of built assets based on $2009 / 2010$ benchmarks, supported by a $50 \%$ reduction in overall time, from inception to completion, for new build and refurbishment assets based upon the UK industry performance in 2013. Achievement of such targets requires a significant change from traditional procurement methods and in the way how construction projects are managed. The Industrial Strategy report found "clear evidence of the fragmentation of the industry and a real demonstration of the challenge of building integrated supply chains' (BIS, 2013, p.56). The report asserted 'plentiful evidence of effective use of frameworks', although such evidence is not specifically cited. Therein lies a dichotomy of suggested approaches - fragmentation of a supply chain encompassed through a structured engagement framework.

Public sector frameworks were developed under EU Directive 2004/18/EC of the European Parliament for 
coordination of procedures for the award of public works contracts, public supply contracts and public service contracts. A prime objective of a framework is to provide stronger relationships through longer term arrangements using engagement with fewer suppliers (Construction Excellence, 2009), providing alignment with initiatives suggested by Latham (1994) and Egan (1998). A framework agreement provides an overarching 'umbrella' contract where projects separated into individual 'work packages' procured at a call-off stage throughout the period of agreement, which is currently set to a maximum of 4 years. The framework agreement is written to allow for a wide range of project characteristics and values as detailed specifications of individual projects are often not well defined at the outset date of the agreement. The majority of framework arrangements are between a client (or conjoined clients) and multiple suppliers.

Research into project management of performance outcomes of collaborative and partnering long term contracts is limited in terms of what and how quality, time and cost benefits can be achieved (Meng, 2012). A recent paper established, through a localised regional UK public sector based case study, that significant improvements are possible through the use of framework agreements (Lam and Gale, 2014). These include quality (lower defects upon completion and higher health and safety standards during construction), time (substantial number of projects finished on time) and cost (significant number of interim payments agreed within $5 \%$ of value and without excessive claims). Other research also suggests that the influence of chosen procurement and engagement method together with conditions of contract may have impact on project outcomes (Forgues and Koskerla, 2008; Koskinen, 2009).

This research aims to build upon such published studies to develop a performance model specifically related to construction framework agreements through identification of performance drivers in the whole project delivery process including pre and post contract phases. This enables the client project managers to effectively collaboratively manage contractor performance within the upper chain.

\section{Sociological Performance Drivers}

The link between organisational culture and productivity/performance is well established, being supported by a substantial number of studies from the field of socio-psychological investigation into teams and groups. Recent research places a progressive stratification of interaction between group culture, group behaviour and group performance. Tellis et al., (2009) concluded that culture drives behaviour for groups at a cognitive level using standard procedures following Zhang and Liu's (2006) 'culture - effectiveness' model. Culture provides motivated behaviour which in turn increases performance with Chinese contractors. In light of such studies, Walker (2011) warned 'research on the impact of culture on organisational performance is mixed' and although cited examples from a range across the cultural spectrum, no definitive conclusions were reached. Nonetheless, a review of the published literature places behaviours as a driver for group performance and in reflection of this organisational behaviour forms the sociological drivers for performance.
A literature review of collaborative centric performance based groups identified characteristics that contributed positive results in outcomes with construction projects (Katzenbach, 2000). Ten significant characteristics identified by Katzenbach were reaffirmed by Akdemir et al. (2010) who ranked 26 characteristics into the most effective ten behaviours. The ten organisational behaviours are collated in Table 1 and supported by other discrete research references.

Traditional behaviour theory directly linked performance to financial payment (Taylor, 1914) where human production is proportional against pecuniary gain. This simplified view was added by development of behaviour theories following investigations into human relations in the workplace by Henry Dennison and Elton Mayo. Mayo (1949) found that individuals desire to stand well amongst the others in the group. Dennison (1925) proposed that removing the fear of unpredictable employment allowed the utilisation of affirmative forces of pride (satisfaction), team spirit and loyalty (relationships), and emulation (group motivation and incentives) (Dennison, 1925). This was reinforced by further studies (Dennison, 1931) where influence upon output performance required an intrinsic mix of nonfinancial incentives, satisfaction, motivation and economic incentive. Proviso to Dennison's conclusions was the essential presence of a long term strong relationship between group members. Within a construction framework group, this refers to the 'long term working relationships' between clients and suppliers. Construction Excellence (2009) explains that longer term relationships allow greater understanding between all participants, thus resulting in higher level of commitment to achieve mutual goals and continuous improvement from engagement of best practice. This means that clients can achieve better project outcomes and suppliers can maximise their profits and have a higher level of satisfaction.

Project outcomes from construction frameworks can therefore be positively associated with the ten organisational behaviours, which can be developed stronger if a longer term is set up for the contract at the pre contract phase. These organisational behaviours are displayed as the sociological construct within the performance model.

\section{Operational Performance Drivers}

Within the construction industry additional monetary payments to encourage increased output set against outturn productivity targets has historically been a popular method of incentive. Bresnen and Marshall (2000) proposed that financial incentives coupled with advanced contracting methods could improve both commitment and motivation within projects. Within the fields of generalised non-specific project management a wide variety of measures are used to describe outcomes of a project and input characteristics that affect outcomes (Banker et al., 1984). Traditionally research into success with construction projects has focussed upon three outcomes - cost, quality and time (Belassi and Tukel, 1996). As projects have become more complex and clients demands more sophisticated, additional outcomes that add value such as long term sustainable development, environmental impact and reliability with use are placed to the fore (Chan and Chan, 2004). 
Table 1. Ten most significant group behaviours

\begin{tabular}{|c|c|c|}
\hline Behaviour & Emphasis & Literature Source Reference \\
\hline Communication & $\begin{array}{c}\text { Improved communication enables groups } \\
\text { to raise performance level }\end{array}$ & Greenberg and Baron (2003) \\
\hline Trust and confidence & $\begin{array}{l}\text { Distribution of fairness with group } \\
\text { participants }\end{array}$ & Culyer (2001) \\
\hline Empowerment & $\begin{array}{c}\text { Decision making process delegated to } \\
\text { individuals }\end{array}$ & Green (2002) \\
\hline Effective incentive system & $\begin{array}{l}\text { Non- financial and financial reward } \\
\text { methods }\end{array}$ & Eriksen (2001) \\
\hline Diversity & $\begin{array}{l}\text { Mixture of group participants and } \\
\text { geographic locations }\end{array}$ & Milakovich and Gordon (2009) \\
\hline Motivation & $\begin{array}{l}\text { Practice of providing purpose and } \\
\text { direction to behaviour }\end{array}$ & Greenberg and Baron (2003) \\
\hline Knowledge transfer & $\begin{array}{c}\text { Tacit knowledge shared between group } \\
\text { participants }\end{array}$ & Keskin (2005) \\
\hline Relationships & $\begin{array}{c}\text { Breaking down barriers and focusing } \\
\text { upon group rather than individual } \\
\text { outcomes }\end{array}$ & McCann (2004) \\
\hline Satisfaction & Achievement of group goal setting & Fischman et al. (2004) \\
\hline Decision making & $\begin{array}{c}\text { Critical thinking and conflict resolution } \\
\text { skills required for } \\
\text { ethical decision making }\end{array}$ & Fischman et al. (2004) \\
\hline
\end{tabular}

Table 2. Operational metric critical success factors

\begin{tabular}{|c|c|c|c|}
\hline $\begin{array}{l}\text { Critical Success } \\
\text { Factor }\end{array}$ & Element & Measure & Metric \\
\hline CSF1A & Starting on time & Time scale & $\begin{array}{l}\text { Proportional - } 100 \text { for starting on the contractual date } \\
\text { and a sliding scale where started late }\end{array}$ \\
\hline CSF1B & Finishing on time & Time scale & $\begin{array}{l}\text { Proportional - } 100 \text { for finishing on the contractual date } \\
\text { and a sliding scale where finished late }\end{array}$ \\
\hline CSF2 & Accuracy of payments & Cost & $\begin{array}{c}\text { Proportional }-100 \text { for a payment submitted within } 5 \% \\
\text { of certified value and then on a sliding scale where } \\
\text { payment values are different }\end{array}$ \\
\hline CSF3 & Right first time & Quality & $\begin{array}{l}\text { Projects completed without defects - binary result }- \text { yes } \\
\qquad 100 \text {, no } 0\end{array}$ \\
\hline CSF4 & $\begin{array}{l}\text { Health, safety and } \\
\text { welfare inspections }\end{array}$ & Quality & $\begin{array}{c}\text { Proportional - percentage of inspections meeting } \\
\text { minimum criteria }\end{array}$ \\
\hline
\end{tabular}


In reflection of the research into critical success factors a constructive approach is taken from measures undertaken to identify a clients' perception of success. Kerzner (2001) reconfirmed previous studies of a client 'iron triangle' of cost, quality and time as critical success factors of project success. The case study used for this research used additional critical success factors' reflecting the connection between a safe work environment and productivity (health, safety and welfare provisions) but essence of the performance model is focused toward the holistic operation rather than individual factors. To this end the interaction of performance outcomes and reward systems is considered the driver of good performance. This view is supported through studies conducted by Tang et al. (2006) which recognised the correlation between direct collaborative tools and collaborative project success. Such operational models are also identified through cooperative procurement in Sweden (Pesamaa et al., 2009) where performance is rewarded through incentivised mechanisms.

In order to test operational metrics and their effectiveness, five critical success factors (CSF) were used within the case study context. The framework suppliers (contractors) received marks on quarterly basis according to the criteria and measures identified in Table 2.

The reward system placed within the operational construct of the performance model consisted of a graded composite aggregation from results. Although conducted within a single framework case study, the framework comprised of eight suppliers (contracting companies) who had undertaken 120 individual projects. For each completed project included within the case study a Project Success Index (PSI) was assigned by use of the Eq. (1):

$$
\text { Project success index }=\sum \frac{(\underline{\mathrm{AS}-\mathrm{MV}}) \times \mathrm{We}}{(\mathrm{SV}-\mathrm{MV})}
$$

Where:

Project success index $=$ measure of success of a project $=$ sum of the indices of individual critical success factors (CSF1A, CSF1B, CSF2, CSF3 and CSF3). The PSI equation is a formalised version of the calculation used by the case study council for performance monitoring, using the critical success factors that the client deems as making the project successful (Yeung et al., 2008).

AS $=$ Actual Score of the critical success factor being measured in accordance with the measurement definitions.

$\mathrm{MV}=$ Minimum percentage value of the critical success factor.

$\mathrm{SV}=$ Stretching percentage value of the critical success factor. The stretching percentage value is the optimised target for suppliers to attain during the life of the project.

$\mathrm{We}=$ Weighting of the critical success factor. Weighting is dependent upon clients' importance of each CSF but for the case study examined an equalised value was applied. Unless clients apply extreme weightings, a sensitivity analysis reveals that Project Success Index values are not significantly varied through weighting apportionment.

Dependent upon aggregated values, suppliers are placed into one of three zones - red, amber or green. The zone positions are used for tender assessment purposes for a succeeding three month period where a green zone supplier will gain a $10 \%$ advantage in tender assessment, an amber zone supplier receives neutral tender assessment and a red zone supplier has a $10 \%$ disadvantage in tender assessment. These results offer a financial advantage or disadvantage for each supplier according to objective and measured past performance that may be used in the selection of suppliers for future projects.

Operation of such incentive based financial systems used to facilitate project success follow propositions made by Bayliss et al. (2004) and Tang et al. (2006). The project success index and the critical success factors are operational tools which measure, compare and contrast performance outcomes of individual projects in order to provide benchmark values. The PSI values are used to detect optimum or below standard performance allowing trends to be detected - for example with a particular supplier, type of project or form of engagement.

The project success indices provide commercial and contractual pressure upon which the operational construct of the proposed performance model is based. As the project success index is operationally centred, it forms an element of the operational construct of the model.

\section{Proposed Model and Research Methods}

Use of cyclic improvement method developed by $\mathrm{Wu}$ and Barnes (2009) but applied to performance measurement and management research provides a dynamic directional property to the performance model. Each component follows discovery of sociological group performance theories and performance management theories applied to the model. The proposed 'priori performance management model' is composed of the following.

- A sociological construct developed from group performance theories consisting of 'ten identified behaviours' placed in a construction industry context.

- An operational construct developed from performance management theories collated from collaborative working and performance management. The construct is related toward 'measurement and operation of key performance outcomes' for determining chance of further projects.

- The focus of the performance model is an impact of 'sociological and operational performance drivers' at pre and post contract phases upon contractors involved within the framework.

The predominant research method used for this research is quantitative, supporting a dominance set within a positivist paradigm used to test the sociological construct of the model. As explained by Dainty (2007), the use of empirical quantitative information assists with compelling evidence in order to objectively discover phenomena. Use of such analytical manipulation of quantitative data provides recognition of variables through a scientific process (Walker, 1997) by giving results subjected to statistical comparison of samples undertaken, measuring these against standardised populations allowing explanatory statements to be made (Czaja and Blair, 1996). In support of the chosen quantitative methods, qualitative 
interviews were conducted seek to understand the views of practitioners on what and how sociological behaviours drive project outcomes - an important feature of sociological group based research. The qualitative interviews with experienced practitioners were also used to confirm and explain the relationship between performance measures and project outcomes - the operational construct of the model.

In construction project management discipline case studies can provide data of highest quality and depth (Wineburg, 1997), but when applied with construction project life cycles, such data requires a long period to amass collection of data, determine views and provide conclusions. This research is set within a paradigm of a single case study in order to explore data and information relevant for a major public sector organisation. The organisation is of sufficient economic mass $(>£ 1 \mathrm{Bn}$ annual turnover) and also has a continuous requirement for construction industry products in delivery of its statutory duties. The organisation also directly employs more than 100 qualified staff, such as engineers and quantity surveyors, with the management of projects allowing access to views from practitioners allied to the construction professions. Furthermore, it is similar to other local authorities in terms of statutory and financial control on procurement of works, thus forming a representative case.

Within the case study, the following source data is available:

- A pilot study with 20 practitioners to gauge initial results through a priori investigation and ascertain if the sociological construct arrived from examination of published literature provided a basis for further enquiry.

- A quantitative questionnaire survey conducted with 100 practitioners (out of an estimated population of $180,55.6 \%$ sample size) from public sector employees and private sector framework contractors. Table 3 refers.

- In-depth interviews with 10 practitioners $(5.6 \%$ sample size) experienced in both framework and traditional discrete projects.

- Factor analysis and central tendency statistics from the 'questionnaires' and qualitative content analysis using node values from the 'interview transcripts' to validate and explain sociological behaviour factors and operational performance measures. Use of quantitative and qualitative approaches in tandem can provide objectivity, generalisation and authenticity to the research (Raftery et al., 1998).

A simple random probability sampling technique was used whereby all 180 participants were chosen through a general contact email - internally to the client organisation and externally to nine suppliers. All nine suppliers had experience of both framework agreements and discrete procurement methods with the client organisation. Within the client organisation, 60 of the 108 participants had a detailed knowledge of framework agreements generally whilst the remainder admitted a cursory and distant awareness. Of the 180 maximum estimated participants, 109 offered to take part in the questionnaire and 100 returned questionnaires that could be used for data collection. Participants who offered to return questionnaires are $60.6 \%$ of the total estimated population and returned usable data is $55.6 \%$ of the total estimated population. These are very high results that meet the 'rule of thumb technique' suggested by Neuman (1994) of 30\% minimum sample size for populations under 1000 .

\section{Findings and Discussion}

\subsection{Pilot Study}

The operational construct using metrics and performance zone was operated for a 24 month period ( 8 consecutive 3 month performance periods) to gather project success index results and establish the incentive mechanism. During this period the significant group behaviour factors were subjected to a pilot study involving 20 participants. Confidence with results from the pilot study confirmed recognition of the same ten behaviours identified from research into characteristics of high performance organisations (Akdemir et al., 2010). This allowed construction of a research questionnaire for further refinement and issue to case study participants. Responses were filtered to remove reverse test questions and the remaining ten questions are included in Table 4 for empirical analysis.

\subsection{Questionnaire Survey: Central Tendency Statistical Analysis}

As a conformational check to the factor analysis, the ten behaviour characteristics tested though responses from participants were subjected to a measure of central tendency using a mean score. For this check, responses were assigned a ranking against participant responses for a Likert scale between 1 and 5 to the manipulated values in Table 5.

The central tendency results provide an indication of the most significant group behaviour characteristics with which to explore in greater detail. Participants do indicate that longer term working relationships between clients and suppliers is of prime importance with successive ordered ranking on communication, trust, motivation and incentives. Although measures of central tendency (in Table 5) represent an approximate method of analysis, further examination through factor analysis was used to identify the underlying trends.

\subsection{Questionnaire Survey: Factor Analysis Results}

Responses from participants to questions regarding ten behaviours for successful group performance included within the questionnaire were subject to an examination of suitability for factor analysis. Inspection of the correlation matrix revealed a significant number of coefficients above 0.3 (68 out of 100). The KMO value was 0.861 and Bartlett's test reached statistical significance supporting use of data for factor analysis. Eigenvalues exceeded 1 for two components, explaining $42.7 \%$ and $10.5 \%$ of the variance respectively. An inspection of the scree plot revealed a break after the second component. To aid with interpretation of the two components, Varimax rotation was performed and showed six strong loadings with three cross loadings. The strongest values loaded substantially on one component in which incentive, decision making, relationships, trust, knowledge transfer and motivation have a factor loading of greater than 0.6. The two component solution explained a total of $53.2 \%$ of the 
variance, with component 1 contributing $33.9 \%$ and component 2 contributing $19.2 \%$.

\subsection{Qualitative Interviews: Content Analysis Results}

Qualitative methods selected for analysis of interview transcripts comprised word frequency, node theme classification and meta-synthesis in order to elicit individual participant statements and these are aggregated into group views. Interpolation of the aggregated group views are designed to represent predominant views of the sociological group class provided that saturation has occurred (Guest et al., 2006). Aggregated coding results synthesised into a structured node tree displayed commonalty with clusters allowing group views to be summarised. The thematic meta-synthesis analysis was used to uncover an interrelated number of key results (or themes) that can be placed according to frequency into a hierarchal structure. Aggregation of results allows strength of a theme to be measured within the sociological group, where higher values represent stronger affirmation to that theme. Fig. 1 shows the structured node tree using the empirical frequency values from all the nine interviewees. A theme of relationships is determined as the prime node due to the highest ordered value. Sub-nodes of relationships are determined by the same process.

The most significant theme concerned relationships, where successful ones improve performance and is operated through incentives (either financial or psychological). The performance node also includes operation of KPI's as part of performance measures. A sub-node to relationships is communication - where aggregated responses had values in excess of 50 for operational factors with contracts (measurement process) and frameworks (performance process). Sociological behaviour was recognised as being more effective than financial rewards as suggested by Thibaut and Kelly (1959) in The Social Psychology of Groups and expanded through a general independence theory by Rusbult et al. (1998). The case study interview results align with this published research as participants recognise satisfaction of sociological needs and rewards more readily through framework arrangements when contrasted with discrete methods.

During interviews with selected participants a number of themes emerged and were recognised as interrelated. The following is a summary of practitioners own views, which confirm the significant sociological and operational factors and explain how they drive project outcomes within the framework project organisation.

- $\quad$ Sociological factors $\}$...encourage a stronger and a closer relationship because you are participating together and as a result you create more common goals and have a key working approach

- $\{$ Sociological factors afford $\}$...better communication and that's more likely to happen in a framework because of the strong relationships

- $\{$ Operational factors\} ...are rewarded with incentives from performance and they are benefiting from that
- $\{$ Operational factors $\}$...enable both sides to look at historical performance data related to the project to identify where the client team and the contractor team members need to improve.

Reflective analysis of the model indicates a strong association of performance with each significant element. The operational construct relied upon use of key performance indicators to measure project outcomes where successful projects could place suppliers for selection of a future project by use of a marginal incentive system related to price and quality assessment. Operation of the construct gave a measurable improvement in project performance outcomes on the projects contained in the case study and this investigation formed a separate research paper (Lam and Gale, 2014). The operational construct of the performance model operates in the manner proposed and in the sequence anticipated. In partial explanation and allied to the Hawthorne studies (Mayo, 1949) the process of measurement and desire to compete appears to provide a strong driver to performance improvement. As participants state:

'... the fact that our performance is being monitored and that monitoring of our performance contributes to our future ability, or not, to secure more work ,... raises the priority to make the customer that bit more important ...'.

'... if you're going to be measured on something it becomes a greater priority for you'.

'... in the public eye with performance data being published ... they will stick to something ...'.

Within the generalised view, individual components, as described by practitioners through their own words in response to interview questions, provided a significant awareness of the drivers of performance. The extent of this is perhaps surprising given the traditional conservative views of the construction industry (Davies, 2008) and realisation that case study participants had less than three years of experience of framework agreements at the time of interview. Coupled with a natural resistance to organisational change proposed by Smollen (2011), the strength of results and engagement of participants with drivers of performance is somewhat significant.

\subsection{Summation of Qualitative and Quantitative Data}

Analysis from factor analysis results provided a significant component with high factor loadings for incentives, decision making, relationships, trust and knowledge transfer. Such significant factor, labelled duration, required a continuance of passage of time with which to gain performance outcomes. A measure of central tendency found three behaviours (relationships, trust and incentive) that aligned with strong factor loadings. Nodal aggregated values taken from interviews provide that relationships, communication and incentives are the most repeated themes. The combination of questionnaire and factor analyses (quantitative evaluation) and interview analysis (nodal aggregation) provides a comprehensive and compelling view of group views which confirm that relationships, communications and incentives as key components of sociological group themes. All the results are summarised in Table 6. 
Table 3. Estimated total population of the case study

\begin{tabular}{ccc}
\hline Organisation & Participant group & Number of participants \\
\hline Client & Design group - highways section & 30 \\
Client & Contracts - quantity surveyors & 8 \\
Client & Design group - structures section & 30 \\
Suppliers - (9 number) & Estimating and contracts & 27 \\
Client & Supervision & 32 \\
Suppliers - (9 number) & Contract management & 45 \\
Client & Strategic project management & 8 \\
\hline
\end{tabular}

Table 4. Identification of behaviour factor questions for empirical analysis

\begin{tabular}{ccc}
\hline Question number & $\begin{array}{c}\text { Predominant sociological behaviour } \\
\text { factor }\end{array}$ & Literature source reference \\
\hline 21 & Relationships (long term) & McCann (2004) \\
22 & Communication & Greenberg and Baron (2003) \\
23 & Decision making & Fischman et al. (2004) \\
24 & Knowledge transfer & Keskin (2005) \\
25 & Incentives & Eriksen (2001) \\
29 & Trust & Green (2002) \\
30 & Empowerment & Milakovich and Gordon (2009) \\
35 & Diversity & Fischman et al. (2004) \\
36 & Satisfaction & Greenberg and Baron $(2003)$ \\
\hline
\end{tabular}

Table 5. Measure of central tendency for the ten behaviours

\begin{tabular}{cccc}
\hline \multirow{2}{*}{ Question number } & $\begin{array}{c}\text { Predominant sociological } \\
\text { behaviour factor }\end{array}$ & Mean & Central Tendency \\
\cline { 3 - 4 } 21 & Relationships (long term) & 3.92 & 1 \\
22 & Communication & 3.49 & 2 \\
23 & Decision making & 3.25 & 7 \\
24 & Knowledge transfer & 3.25 & 7 \\
25 & Incentives & 3.30 & 4 \\
29 & Trust & 3.35 & 3 \\
30 & Empowerment & 2.31 & 9 \\
35 & Diversity & 3.21 & 6 \\
36 & Satisfaction & 3.26 & 4 \\
\hline
\end{tabular}

Table 6. Summation of significant behaviour results

\begin{tabular}{cccccc}
\hline $\begin{array}{c}\text { Loaded factors from } \\
\text { factor analysis }\end{array}$ & $\begin{array}{c}\text { Rotated } \\
\text { component } \\
\text { value }\end{array}$ & $\begin{array}{c}\text { Central tendency } \\
\text { from questionnaire }\end{array}$ & $\begin{array}{c}\text { Mean } \\
\text { value }\end{array}$ & $\begin{array}{c}\text { Significant } \\
\text { qualitative nodes } \\
\text { from interviews }\end{array}$ & Node aggregate value \\
\hline Relationships & 0.725 & $\begin{array}{c}\text { Relationships } \\
\text { Communication }\end{array}$ & $\begin{array}{c}3.92 \\
\text { Trust }\end{array}$ & $\begin{array}{c}\text { Relationships } \\
\text { Communication }\end{array}$ & 174.56 \\
Incentives & 3.35 & & 56.99 \\
Incentives & 0.778 & Motivation & 3.30 & Incentives & \\
Decision making & 0.772 & & & & \\
$\quad \begin{array}{c}\text { Trust } \\
\text { Knowledge transfer }\end{array}$ & 0.636 & 0.608 & & & \\
\hline
\end{tabular}




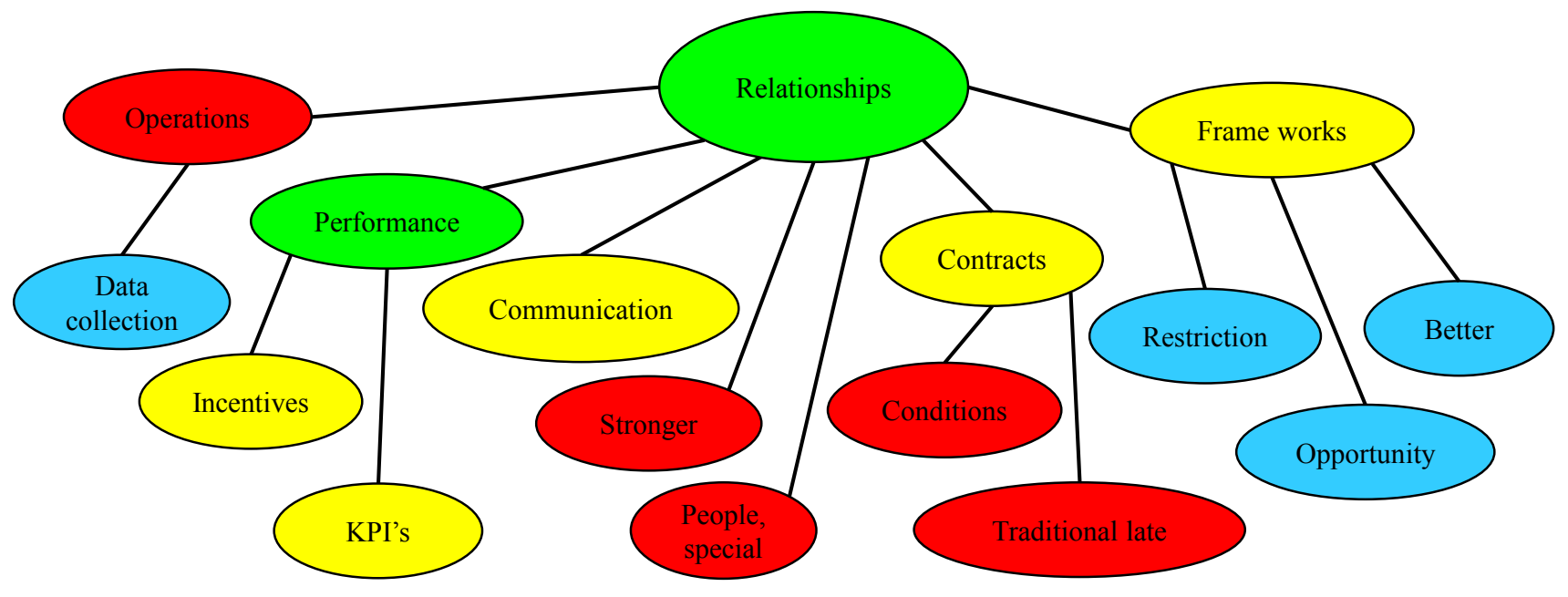

Fig. 1. Structured node tree showing hierarchal results

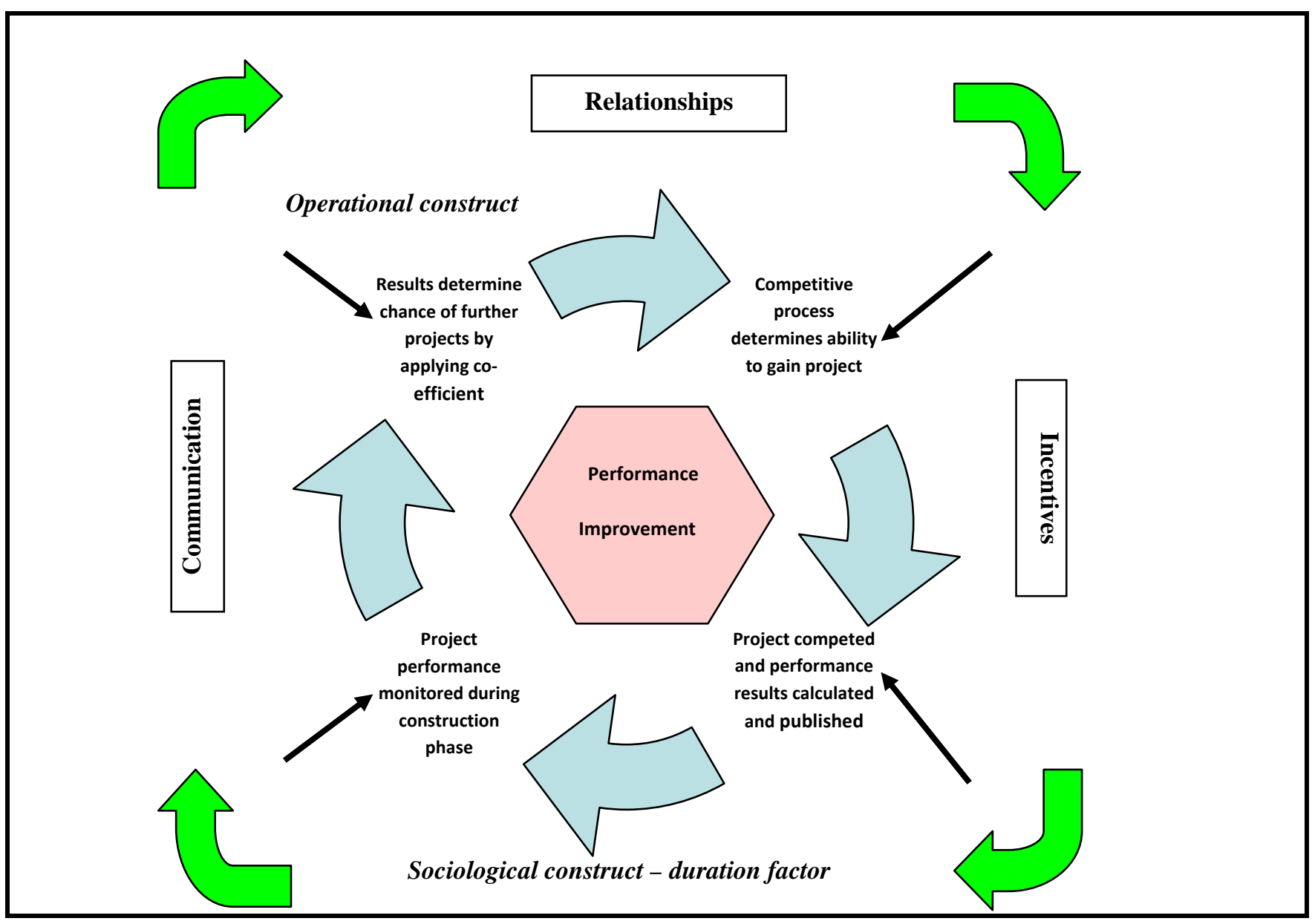

Fig. 2. A posteriori procurement performance model for construction frameworks

\section{Construction of Performance Model}

The tripartite data collection - pilot, questionnaire and interview - where results align provides confidence to conclusions made with the performance model, as shown at Fig. 2.

Completion of the analytical phase of the research allows revaluation of performance model. Following an initial pilot placement of components, two constructs were prevalent. Construct one consisted of the operation of incentives through collection of project data being compiled into performance zones and forming incentivised drivers to encourage and maintain project performance levels. In the model construct one is labelled the operational construct. The influence of organisational group behaviour upon performance outcomes through integration of views from a class of technical professions is represented through construct two and this is labelled sociological construct. 
Data analysis collated for the posteriori model provided confirmation that the original constructs of the priori model remained unchanged. The pilot study, which comprised a qualitative enquiry of views from 20 construction professionals matched with outcome performance data collected from 20 framework projects, allowed recognition of a sociological and operational construct. When questioned further, the majority of selected participants suggested that performance improvements combined sociological behavioural changes with measured project outcomes from operational effects. The pilot study allowed proposition of the priori model upon which a larger examination involving 100 participants (involved in 120 construction projects) was conducted. The posteriori model confirmed views - often through obiter dicta remarks, of two distinct areas correlating with the constructs of the model. As with the pilot study, a significant number of participants in the extended study suggested that improved performance would be achieved through distinct sociological and operational constructs. At the centre of both models, performance and the desire to improve also remained constant due to psychological incentive desire to stand well amongst the others in the group and to competition arising from performance measurement and monitoring, as discussed in Section 5.4. Examination of each construct is undertaken to identify changes in the elemental components which appear in the construct. For the sociological construct, the priori model identified incentives, motivation, satisfaction and relationships as prime behavioural components arising from a pilot study. Prime behavioural components for the posteriori model following factor analysis, central tendency and qualitative node aggregation placed relationships, incentives and communication at the fore. The predominant underlying factor for the sociological construct was duration. Obviously longer duration of framework allows stronger relationships and communication to be developed between participants as well as more non-financial and financial incentives to be gained by contractors.

It was clear through examination with published research and the methods used for this study that each construct, operational or sociological, had the capability of independent performance improvement, but operating together produced a vortex effect where one construct had an immeasurable but recognisable (by participants) influence upon the other. In Fig. 2 the relationship between the two constructs is suggested through thin arrows. Participants mentioned behavioural factors and performance measures as interlinked for performance outcomes but it has been difficult to measure the extent of effect this has on performance outcomes. Nonetheless examples of such holistic approaches displayed by participants rather than viewing individual constructs are:

'... you've got a system which balances the reward for positive or negative performance on issues other than financial ones and I think that's a balance you've got quite good ...'.

'... in the framework I think the incentives... of good performance benefiting their next submission in terms of appraising, and the competition improves performances...'.

\section{Conclusions}

Through a literature review and application of research methods, a model is developed for performance improvement through use of collaborative framework methods. Reflection of the performance model confirms that operational methods at the post contract phase drive performance as anticipated and that these are readily accepted by participants. Use of contract KPIs (project success index and individual critical success factors) for performance measurement provides a focus upon performance outcomes provided these engage with operational methods used by construction management (key dates for projects, contractual records and the like). Synthesis of results identifies three significant behaviours for performance improvement: relationships, incentives, communication, which are set within a factor of duration. The underlying factor of duration infers that longer term should be set at the pre contract phase for construction frameworks to allow development of the three significant behaviours. This means that stronger relationships and communication can be developed between participants and that more incentives can be gained by contractors, and consequently all of these drivers augment performance and project incomes.

Results from the posteriori procurement performance model have been incorporated into a second generation collaborative framework set within the South East Region of the UK. An examination of project outcomes indicate that data compiled as of June 2014 displays performance improvement effect comparable to results included in research conducted by Lam and Gale (2014). The deduction, by inference, is that provided elements of the model in this paper are included in collaborative procurement systems, such results can be expected to continue. As the model displays geared influence, critical success factors and project success outcomes are expected to remain at the fore of participant's objectives, enhanced by the pressure to perform. Practically client project managers can use the performance model developed to effectively manage the upper chain and drive the project outcomes in construction framework contracts through procurement measures, in particular longer contract term and use of KPIs. In relation to the theoretical implication, the research findings make significant contribution to the construction framework procurement by identifying the interrelated sociological and operational performance drivers in the whole project delivery process including pre and post contract phases.

This case study is set predominantly in the field of highways civil engineering. This has allowed detailed comparison of outcomes due to containment within a specific classification, but other types of projects could be explored. It is suggested that building based projects or other projects that share characteristics are grouped together and used for further research of the phenomena discovered. Contextual placement of this research is limited to construction projects set within the public sector and subject to European legislation and UK regulation. The influence of latter legal restrictions may be significant when transferred to other counties. It is also suggested that this study is replicated in other countries where collaborative framework agreements display similar characteristics in order for comparative analysis to be undertaken. Lastly, further research should be conducted to examine the performance of supplier chain so that a total performance model can be developed to include the interface between the main contractor and subcontractors, 
which is considered to be important for successful project outcomes by White and Marasini (2013).

\section{References}

Akdemir, B., Erdem, O., and Polat, S. (2010). Characteristics of High Performance Organisations. Journal of Faculty of Economics and Administrative Sciences, 15(1), 155-174.

Banker, R.D., Charnes, A., and Cooper, W.W. (1984). Some models for estimating technical and scale inefficiencies in data development analysis. Management of Science, 30(9), 1078-1092.

Bayliss, R., Cheung, S., Suen, H., and Wong, S.P. (2004). Effective partnering tools in construction: a case study on MTRC TKE contract in Hong Kong. International Journal of Project Management, 14(3), 141-151.

Belassi W. and Tukel, O. (1996). A new framework for determining critical success/failure factors in projects. International Journal of Project Management, 14(3), 141-151.

BIS (2013). Industrial Strategy: government and industry in partnership, Construction 2025. London: Department for Business, Innovation \& Skills (BIS).

Bresnen, M. and Marshall, N. (2000). Motivation, commitment and the use of incentives in partnerships and alliances. Journal of Construction Management and Economics, 18(5), 587-598.

Cabinet Office (2011). Government Construction Strategy. London: Cabinet Office.

Chan, A. and Chan, A. (2004). Key performance indicators for measuring construction success. Benchmarking: An International Journal, 11(2), 203221.

Construction Excellence (2009). Never waste a good crisis - a review of progress since rethinking construction and thoughts for our future, London: Construction Excellence.

Cresswell, J.W. (2003). Research design: qualitative, quantitative and mixed method approaches, California: Sage Publications.

Culyer, A. (2001). Equity: some theory and its policy implications. Journal of Medical Ethics, 27(4), 275283.

Czaja, R. and Blair, J. (1996). Designing surveys: A guide to decisions and procedures, California: Thousand Oaks, California.

Dainty, A.R.J. (2007). A review and critique of construction management research methods. In: W, Hughes, eds. Proceedings of Construction Management and Economics $25^{\text {th }}$ Anniversary Conference, 16-18 July, University of Reading, 15331544.

Davies, K. (2008). Barriers or constraints? A review of development issues as they apply to construction IT. International Conference on Information Technology in Construction Santiago, Chile CIB W78 2008, 239245.

Dennison, H.S. (1925). The need for an applied psychology of organisation. American Management
Association, Annual Convention Series: No. 13, New York: AMA, 1925.

Dennison, H.S. (1931). Organizational Engineering. Reprint 1972, PA: Hive Publishing.

Eriksen, E.O. (2001). Leadership in a communicative perspective. Acta Sociologica, 44(1), 21-35.

Egan, J. (1998). Rethinking Construction: Department of Trade and Industry (Construction Task Force), London: Her Majesty's Stationary Office.

Fischman, W., Becca, S., Deborah, G., and Howard, G. (2004). Making good, how young people cope with moral dilemmas at work, Massachusetts: Harvard University Press.

Forgues, D. and Koskela, L., 2008. Can procurement affect design performance? Journal of Construction Procurement, 14(2) 130-141.

George, A.L. and Bennett, A. (2005). Case studies and theory development in the social sciences, Massachusetts: MIT Press.

Green, S. (2002). The human resource management implications of lean construction: critical perspectives and conceptual chasms. Journal of Construction Research, 3(1), 147-165.

Greenberg, J. and Baron, R. (2003). Behavior in organizations, NJ: Prentice Hall.

Guest, G., Bunce, A., and Johnson, L. (2006). An experiment with data saturation and variability. Field Methods, 18(1), 59-82.

Katzenbach, J.R. (2000). Peak Performance, Massachusetts: Harvard Business School Press.

Kerzner, H. (2001). Strategic Planning for Project Management using a Project Management Maturity Model, New York: J Wiley.

Keskin, H. (2005). The relationships between explicit and tacit oriented KM strategy, and firm performance. Journal of American Academy of Business, 7(1), 169. 175.

Lam, T. and Gale, K. (2014). Highway maintenance: impact of framework agreements on contractor performance. Engineering. Construction and Architectural Management, 21(3), 336-347.

Latham, M. (1994). Constructing the team: final report of the government/industry review of procurement and contractual arrangements in the UK construction industry. London: Her MMSO.

Mayo, E. (1949). The Social Problems of an Industrial Civilization, Reprint 1975, London: Routledge.

McCann, J. (2004). Organizational effectiveness: changing concepts for changing environments. Human Resource Planning, 27(1), 42-50.

Meng, X., Sun, M., and Jones, M. (2012). Maturity model for supply chain relationships in construction. Journal of Management in Engineering, 27(2), 97-105.

Milakovich, M. E. and Gordon, G. J. (2009). Public administration in America, California: Wadsworth. 
Mintzberg, H. (1979). The structuring of organisations: a synthesis of research, NJ: Prentice-Hall.

Neuman, W.L. (1994). Social research methods: qualitative and quantitative approaches, Massachusetts: Allyn and Bacon.

ONS (2010). Construction statistics annual 2010, Newport: Office for National Statistics.

ONS (2011). Economic and labour market review, Volume 5 number 4, April 2011, Newport: Office for National Statistics.

Pesamaa, O., Eriksson, P.E., and Hair, J. (2009). Validating a model of cooperative procurement in the Swedish construction industry. International Journal of Project Management, 27(6), 552-559.

Raftery, J., McGeorge, D., and Walters, M. (1997). Breaking up methodological monopolies: a multiparadigm approach to construction management research. Construction Management and Economics, 15(3), 291-297.

Rusbult, C.E., Martz, J.M., and Agnew, C.R. (1998). The Investment Model Scale: Measuring commitment level, satisfaction level, quality of alternatives and investment size. Personal Relationship, 5, 357-391.

Smollan, R.K. (2011). The multi-dimensional nature of resistance to change. Journal of Management and Organization, 17(6), 828-849.

Tang, W., Duffield, C., and Young, D. (2006). Partnering mechanism in construction: an empirical study on the Chinese construction industry. Journal of Construction Engineering and Management, 132(3), 217-229.

Taylor, F.W. (1914). The principles of scientific management, New York: Harper and Bros.

Tellis, G.S., Prabhu, J.C., and Chandy, R.K., 2009. Radical innovation across nations: The pre-eminence of corporate culture. Journal of Marketing, 73 (1), 3-23.

Thibaut, J.W. and Kelly, H.H. (1959). The social psychology of groups, New York: Wiley.

Walker, D.H.T. (1997). Choosing the appropriate research methodology. Construction Management and Economics, 15(2), 149-155.

Walker, A. (2011). Organizational Behaviour in Construction, Chichester: Wiley Blackwell.

White, H. and Marasini, R. (2013). Management of interface between main contractor and subcontractors for successful project outcomes. Journal of

Surveyors and Chartered Institute of Arbitrators.
Engineering, Project, and Production Management, 4(1), 36-35.

Wineburg, S. (1997). Beyond "breadth and depth": subject matter knowledge and assessment. Theory into Practice, 36(4), 256-263.

Wu, C. and Barnes, D. (2009). A model for continuous improvement in supplier selection in Agile supply chains. Knowledge and Process Management, 16(3), 85-110.

Yeung, J.F.Y., Chan, A.P.C., and Chan, D.W.N. (2008). Establishing quantitative indicators for measuring the partnering performance of construction projects in Hong Kong. Construction Management and Economics 26(3), 277-301.

Zhang, S., Liu, A. (2006). Organisational culture profiles of construction enterprises in China. Construction Management and Economics, 24, 817-828.

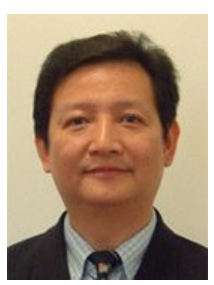

Dr. Terence Lam is a Senior Lecturer in Construction \& Building Surveying at the School of Natural and Built Environment, University of South Australia. His research and teaching interests lie in construction project management, facilities and property management and building surveying, specialising in performance assessment, modelling and prediction of construction consultants and contractors for procurement and outsourcing processes. He is a fellow member of the Royal Institution of Chartered Surveyors and has years of experience in professional practice in property and construction. His research thus focuses to improve the professional practice.

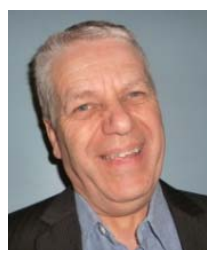

Dr. Keith Gale has significant professional experience in private and public sector organisations. $\mathrm{He}$ is currently the Chief Engineer (Contracts) at Hampshire County Council in the UK, managing infrastructure projects up to individual values of $£ 20 \mathrm{~m}$ within a capital annual programme of $£ 75 \mathrm{~m}$ per annum, as well as frameworks and term contracts for works and services up to $£ 450 \mathrm{~m}$ in value. He is also a Visiting Fellow at the Department of Engineering \& Built Environment, Anglia Ruskin University in the UK and has published in the area of construction frameworks in public sector. He is a member of the Royal Institution of Chartered 